\title{
The association between ambient fine particulate matter and incident adenocarcinoma subtype of lung cancer
}

Lida Gharibvand', W. Lawrence Beeson ${ }^{2,3}$, David Shavlik4, Raymond Knutsen²,3, Mark Ghamsary², Samuel Soret ${ }^{4^{\wedge}}$ and Synnove F. Knutsen ${ }^{2,3,5^{*}}$ (i)

\begin{abstract}
Background: Adenocarcinoma (AC) is the most common lung cancer among non-smokers, but few studies have assessed the effect of $\mathrm{PM}_{2.5}$ on AC among never smokers. The purpose of this study was to assess the association between ambient PM 2.5 and incident lung AC in the Adventist Health and Smog Study-2 (AHSMOG-2), a cohort of 80,044 non-smokers (81\% never smokers) followed for 7.5 years (597,177 person-years) (2002-2011).
\end{abstract}

Methods: Incident lung AC was identified through linkage with U.S. state cancer registries. Ambient PM 2.5 levels at subjects' residences were estimated for the years 2000 and 2001, immediately prior to study start.

Results: A total of 164 incident lung AC occurred during follow-up. Each $10 \mu \mathrm{g} / \mathrm{m}^{3}$ increment in $\mathrm{PM}_{2.5}$ was associated with an increase in the hazard rate of lung AC $[H R=1.31$ (95\% confidence interval (Cl) 0.87-1.97)] in the single-pollutant model. Excluding those with prevalent non-melanoma skin cancer (NMSC) strengthened the association with lung $A C\left(H R=1.62(95 \% \mathrm{Cl}, 1.11-2.36)\right.$ for each $10 \mu \mathrm{g} / \mathrm{m}^{3} \mathrm{PM}_{2.5}$ increment. Also, limiting the analyses to subjects who spent more than $1 \mathrm{~h}$ /day outdoors, increased the estimate ( $\mathrm{HR}=1.55,95 \% \mathrm{Cl}: 1.05,2.30)$.

Conclusions: Increased risk of AC was observed for each $10 \mu \mathrm{g} / \mathrm{m}^{3}$ increment in ambient $\mathrm{PM}_{2.5}$ concentrations. The risk was higher among those without prevalent NMSC and those who spent more than $1 \mathrm{~h} /$ day outdoors.

Keywords: Air pollution, Lung adenocarcinoma, Lung cancer, Particulate matter, Adventists, Non-smokers, Nonmelanoma skin cancer

\section{Background}

According to the American Cancer Society (ACS), lung adenocarcinoma $(\mathrm{AC})$ is the most common subtype of lung cancer (LC) in non-smokers and more likely to occur in females and younger people [1]. An estimated 224,390 new cases of LC overall and about 90,000 incident lung AC cases (approx. $40 \%$ of LC) are expected in the U.S. in 2016 [2]. The temporal increase of AC incidence is causing concern [3-9] as the annual age-adjusted incidence rates of lung AC increased by $2.8 \%$ for women and $1.3 \%$ for men from 2004 to 2009 [4]. An ecological U.S. study

\footnotetext{
* Correspondence: sknutsen@llu.edu

'Deceased

${ }^{2}$ Center for Nutrition, Healthy Lifestyle, and Disease Prevention, School of

Public Health, Loma Linda University, Loma Linda, CA, USA

${ }^{3}$ Adventist Health Study-2, School of Public Health, Loma Linda University,

Loma Linda, CA, USA

Full list of author information is available at the end of the article
}

concluded that long-term exposure to nitrogen oxides $\left(\mathrm{NO}_{\mathrm{x}}\right)$ may play a major role in the increase of lung $\mathrm{AC}$ over the last 50 years [7]. However, to our knowledge, $\mathrm{NO}_{2}$ has never been reported as a carcinogen and the International Agency for Research on Cancer (IARC) states that there is a lack of evidence for $\mathrm{NO}_{\mathrm{x}}$ as an independent cancer risk factor, supported by a recent metaanalysis [10] showing only an increase of $4 \%$ in LC incidence for each $10 \mu \mathrm{g} / \mathrm{m}^{3}$ increase in $\mathrm{NO}_{2}$.

Ambient fine particulate matter $\left(\mathrm{PM}_{2.5}\right)$, on the other hand, is associated with risk of overall lung cancer [11-18], but the relationship between $\mathrm{PM}_{2.5}$ and incident lung $\mathrm{AC}$ has been less studied [12, 13, 19].

In 2013, the International Agency for Research on Cancer (IARC) concluded that exposure to outdoor air pollution causes lung cancer and classified outdoor air pollution in general and particulate matter $(\mathrm{PM})$ in 
particular, as a Group 1 carcinogen to humans [20]. This conclusion was based on findings from several studies, especially the recent results from the European Study of Cohorts for Air Pollution Effects (ESCAPE) [13] as well as a meta-analyses study [21].

We have recently reported a positive and relatively strong association between ambient fine particulate air pollution $\left(\mathrm{PM}_{2.5}\right)$ and overall $\mathrm{LC}$ incidence in the Adventist Health and Smog Study-2 (AHSMOG-2), with HR's ranging from 1.43 to 1.68 , depending on model, for each $10 \mu \mathrm{g} / \mathrm{m}^{3}$ increment in $\mathrm{PM}_{2.5}$ [22]. In the present study, we have assessed the association between ambient $\mathrm{PM}_{2.5}$ and incident $\mathrm{AC}$ of the lung. We also studied the independent association between ambient $\mathrm{O}_{3}$ and LC incidence in a two-pollutant model with $\mathrm{PM}_{2.5}$ because of our previous findings of such association [23]. All study subjects were non-smokers, with $81 \%$ being never smokers, thus virtually eliminating the confounding effect of smoking.

\section{Methods}

\section{Study population}

The study population is the U.S. portion of the Adventist Health Study-2 (AHS-2), a large cohort study of about 96,000 subjects that has been described in detail elsewhere [24]. At enrollment, subjects completed a large 50-page questionnaire which can be viewed at www.adventisthealthstudy.org. Subjects were excluded from the current analysis if they were not linked with state cancer registries (Canadians and subjects living in Maine where we were not able to obtain permission to link with the state cancer registry) $(n=5550)$; had incomplete address information making it impossible to estimate residence specific air pollution concentrations $(n=677)$; reported prevalent cancers except non-melanoma skin cancer $(n=7412)$; were current smokers $(n=249)$ or had missing values on important covariates $(n=2537)$. These exclusions resulted in an analytic study population of 80,044 subjects (Fig. 1).

Written informed consent was obtained from all participants upon enrollment into the parent study (AHS-2) and this included subsequent analysis using de-identified data. The study was approved by the Loma Linda University Institutional Review Board.

\section{Outcome assessment}

Incident cases were classified by the International Classification of Diseases for Oncology (ICD-O-3) codes C34.0-C34.9, with morphology codes including M-8046, $8140,8200,8250,8252-8253,8255,8480-8481$, and 8550 which were identified through computer-assisted record linkage with state cancer registries for the years 2002-2011. Subjects also completed several biennial mailed questionnaires regarding newly diagnosed cancers.

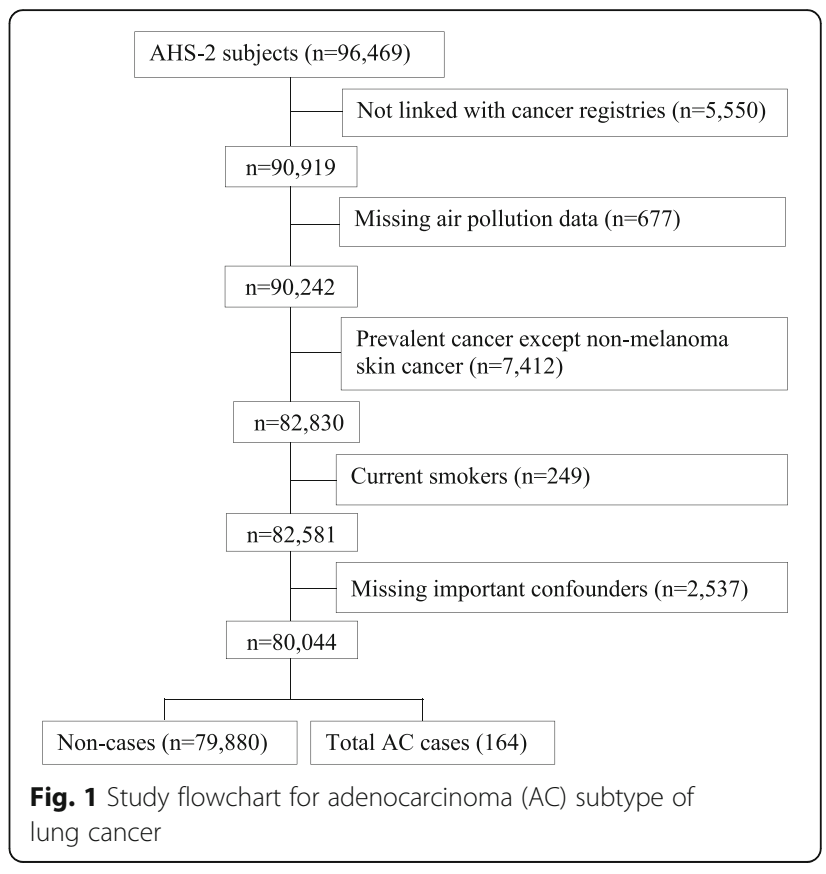

If such self-reported cancers were not verified through the cancer registry linkage, medical records were obtained to verify such cases [24]. The outcome in this study was primary AC of the lung with histology classification of "adenocarcinoma". We also included histology code "8046" even though this code is specified as non-small cell carcinoma. Other types of incident LC, e.g. non-AC LC $(n=94)$ were censored at the time of diagnosis. In addition to linkage with the various state cancer registries, subjects were also linked with the National Death Index (NDI) to ascertain death during follow-up.

\section{Estimation of ambient air pollution concentrations}

Ambient air pollution data were obtained from the U.S. Environmental Protection Agency (EPA) Air Quality System (AQS) for the fixed time period from January 2000 through December 2001, the 2 years immediately prior to the start of the AHSMOG-2 study. Based on the EPA AQS data and Geographic Information Systems (GIS)-based inverse-distance-weighted (IDW) interpolations, multiple monthly pollution surfaces were created for $\mathrm{PM}_{2.5}$ and $\mathrm{O}_{3}$ across the U.S. using ArcGIS software [25]. To minimize errors, the IDW interpolation parameters were selected by assessing the goodness of fit of alternative model configurations through mean prediction error and root-mean-square error estimates. Only months with at least $75 \%$ valid data were included in the exposure estimates. Monthly exposure averages were based on daily $\mathrm{PM}_{2.5}$ and hourly $\mathrm{O}_{3}$ (24-h average). The GIS-derived monthly exposure averages were used to accumulate and assign monthly concentrations of 
ambient $\mathrm{O}_{3}$ and $\mathrm{PM}_{2.5}$ to the geocoded baseline residential street level address of the subjects.

\section{Study covariates}

Covariates for the model were selected a priori based on published studies and suspected relationships and included gender, race, smoking status, years since subject quit smoking, average number of cigarettes per day during all smoking years and educational level. Additional candidate covariates included calendar time, alcohol consumption, family income, body mass index (BMI), physical activity, and marital status.

Three additional variables were identified a priori as potential confounders and/or effect modifiers: hours/day spent outdoors, years of pre-study residence length at enrollment address and moving distance from enrollment address during follow-up.

Since non-melanoma skin cancer (NMSC) has been found, in some studies, to increase the risk of non-skin cancers including lung cancer [26-29], we also decided a priori to do sensitivity analyses excluding those with NMSC at baseline.

\section{Statistical analysis}

Baseline characteristics of cases and non-cases were compared using Chi-square test for categorical and Student t-test for continuous variables. Cox proportional hazards regression modeling, with attained age as the time variable with left truncation by age at study entry, was used for multivariable analyses. The Cox regression was augmented by adding the sandwich variance estimate [30] to adjust for correlated observations within each county. Participants were censored at time of diagnosis or, for non-cases, at the time of last linkage with the cancer registry or date of death, whichever came first.

Single- $\left(\mathrm{PM}_{2.5}\right)$ and two-pollutant $\left(\mathrm{PM}_{2.5}\right.$ and $\left.\mathrm{O}_{3}\right)$ analyses were conducted to assess the role of ambient $\mathrm{PM}_{2.5}$ on lung AC incidence. Pollutants were entered into the model as continuous variables and hazard ratios (HR) were calculated for an increment of $10 \mu \mathrm{g} / \mathrm{m}^{3}$ for $\mathrm{PM}_{2.5}$ and $10 \mathrm{ppb}$ for average 24-h $\mathrm{O}_{3}$. The lowest increment for $\mathrm{PM}_{2.5}$ started with the lowest estimate of ambient air pollution registered in the study population.

The multivariable model was specified based on the pollutant(s) and the a priori selected covariables. Smoking was used as a nested covariate (smoke status + [smoke status $\times$ years since quit smoking] $+[$ smoke status $\times$ years since quit smoking $\times$ cigarettes per day]). We dichotomized years since quit smoking $(<20$ and $\geq 20)$, and number of cigarettes per day $(<8.5$ and $\geq 8.5)$ based on the median levels. The additional candidate covariables (calendar time, alcohol consumption, family income, body mass index (BMI), physical activity, and marital status) were evaluated for inclusion in the model, but adding them did not change the main effect and they were therefore not included in the final model.

The three additional a priori potential effect modifiers (time spent outdoors, residence length and moving distance during follow-up) were then all added to Model 1 as covariates. When testing for effect modification by smoking, it was important to compare our findings with that of others. Therefore, the nested smoking variable was replaced by a dichotomized smoking variable (quit smoking $<10$ years ago and quit smoking $\geq 10$ years ago combined with never smokers) which previously has been used by the Nurses' Health Study (NHS) when testing for effect modification of air pollution and lung cancer [12]. Additionally, a subgroup analyses was also performed to separately assess the risk estimates for $\mathrm{PM}_{2.5}$ on lung $\mathrm{AC}$ in past and never smokers.

The Cox HR proportionality assumption was evaluated using Schönfeld residuals, $\log (-\log )$ plots, and time (attained-age) product terms and no departure from proportionality was evident. Furthermore, using multiple linear regressions, no multicollinearity was evident between covariates. Assessment of Schönfeld residuals did not show important influential data points. The linearity assumptions for the exposure variables were tested and were not in violation of the proportional hazards assumption. All statistical analyses were performed using SAS 9.4 (SAS Institute, Inc. Cary, NC).

\section{Results}

\section{Study population description}

One hundred and sixty four histologically confirmed lung AC cases (27.5 cases per 100,000 person-years) were diagnosed during a median follow-up of 7.5 years (597,177 person-years). Cases tended to be older, past smokers, have lower educational levels, spend more time outside, were more likely to have used alcohol and had lived longer at their enrollment address. They were also more likely to have quit smoking more recently, to have been heavier smokers; and to report prevalent nonmelanoma skin cancer (Table 1). During follow-up, 20\% of the subjects $(n=15,998)$ moved more than $30 \mathrm{~km}$ away from their baseline place of residence while $61 \%$ ( $n=48,960)$ did not move during follow-up.

Non-cases consisted mainly of never smokers, $81 \%$ ( $n=64,817)$, with the remaining $19 \%(n=15,063)$ being past smokers. In contrast, among the 164 lung AC cases, 89 (54\%) were never smokers while $75(46 \%)$ were past smokers (Table 1). The average 24-h ozone concentrations for subjects without and with lung AC were 26.9 (range: 14.1-46.7) and 27.1 (range: 18.3-41.9) ppb, respectively, while mean $\mathrm{PM}_{2.5}$ concentrations were 12.9 (range: $4.1-26.5$ ) and 13.1 (range: $5.3-22.4$ ) $\mu \mathrm{g} / \mathrm{m}^{3}$, respectively. Figure 2 shows adenocarcinoma subtype of lung cancer cases $(n=164)$ overlaid on a $\mathrm{PM}_{2.5}$ monthly 
Table 1 Selected characteristics of the study population at baseline

\begin{tabular}{|c|c|c|c|}
\hline Characteristics & $\begin{array}{l}\text { Non-Cases } \\
(n=79,880)\end{array}$ & $\begin{array}{l}\text { Cases } \\
(n=164)\end{array}$ & P-Valve \\
\hline Age & $57.02 \pm 14.22$ & $68.07 \pm 10.85$ & $<.001$ \\
\hline $\mathrm{PM}_{2.5}\left(\mu \mathrm{g} / \mathrm{m}^{3}\right)$ & $12.88 \pm 3.72$ & $13.11 \pm 3.98$ & $<.001$ \\
\hline Ozone 24 h (ppb) & $26.88 \pm 3.89$ & $27.07 \pm 4.22$ & $<.001$ \\
\hline Gender & & & 0.730 \\
\hline Females & $52,067(65.2 \%)$ & $109(66.5 \%)$ & \\
\hline Males & $27,813(34.8 \%)$ & $55(33.5 \%)$ & \\
\hline Smoking Status & & & $<.001$ \\
\hline Never Smokers & $64,817(81.1 \%)$ & $89(54.3 \%)$ & \\
\hline Past smokers & $15,063(18.9 \%)$ & 75 (45.7\%) & \\
\hline Race & & & 0.599 \\
\hline Blacks & $57,461(71.9 \%)$ & $121(73.8 \%)$ & \\
\hline Non-Blacks & $22,419(28.1 \%)$ & $43(26.2 \%)$ & \\
\hline Education & & & $<.001$ \\
\hline High school or less & $21,820(27.3 \%)$ & $77(47.0 \%)$ & \\
\hline $\begin{array}{l}\text { Trade school/ associate } \\
\text { degree/ some college }\end{array}$ & $27,112(33.9 \%)$ & $52(31.7 \%)$ & \\
\hline Bachelor degree+ & $30,948(38.7 \%)$ & $35(21.3 \%)$ & \\
\hline Family Income & & & $<.001$ \\
\hline Less than $\$ 31,000$ & $41,247(51.6 \%)$ & $110(67.1 \%)$ & \\
\hline$\$ 31,000-\$ 75,000$ & $23,534(29.5 \%)$ & $41(25.0 \%)$ & \\
\hline$\$ 75,000$ or more & 15,099 (18.9\%) & $13(7.9 \%)$ & \\
\hline Body Mass Index $\left(\mathrm{kg} / \mathrm{m}^{2}\right)^{\mathrm{a}}$ & & & 0.280 \\
\hline Less than 25 & $30,411(39.3 \%)$ & $54(34.4 \%)$ & \\
\hline $25-29.99$ & $27,034(34.9 \%)$ & $64(40.8 \%)$ & \\
\hline 30 or more & $19,993(25.8 \%)$ & $39(24.8 \%)$ & \\
\hline Physical Activity & & & 0.290 \\
\hline Low & $31,401(39.3 \%)$ & $74(45.1 \%)$ & \\
\hline Medium & $33,472(41.9 \%)$ & 64 (39.0\%) & \\
\hline High & $15,007(18.8 \%)$ & $26(15.9 \%)$ & \\
\hline $\begin{array}{l}\text { Hours Per Day Spent } \\
\text { Outdoors }\end{array}$ & & & 0.003 \\
\hline Less than $1 \mathrm{~h} /$ day & $19,508(24.4 \%)$ & 39 (23.8\%) & \\
\hline 1-3.5 h/day & $45,156(56.5 \%)$ & 77 (47.0\%) & \\
\hline More than 3.5 h/day & $15,216(19.1 \%)$ & $48(29.3 \%)$ & \\
\hline Alcohol Status $^{a}$ & & & $<.001$ \\
\hline Never & 46,935 (59.1\%) & $73(44.8 \%)$ & \\
\hline Ever & 32,537 (40.9\%) & $90(55.2 \%)$ & \\
\hline Residence Length ${ }^{\mathrm{b}}$ & & & $<.001$ \\
\hline Less than 5 years & 19,924 (25.0\%) & $29(17.7 \%)$ & \\
\hline $5 \leq$ years $<12$ & $20,583(25.8 \%)$ & $32(19.5 \%)$ & \\
\hline $12 \leq$ years $<24$ & $19,713(24.7 \%)$ & $43(26.2 \%)$ & \\
\hline More than 24 years & $19,660(24.6 \%)$ & $60(36.6 \%)$ & \\
\hline
\end{tabular}

Table 1 Selected characteristics of the study population at baseline (Continued)

\begin{tabular}{llll}
\hline $\begin{array}{l}\text { Moving Distance } \\
\text { C KM }\end{array}$ & $48,865(61.2 \%)$ & $95(57.9 \%)$ & \\
$0<$ KM $\leq 30$ & $15,054(18.9 \%)$ & $32(19.5 \%)$ & \\
More than 30 KM & $15,961(20.0 \%)$ & $37(22.6 \%)$ & \\
$\begin{array}{l}\text { Years Since Quit Smoking } \\
\text { (7 levels) }\end{array}$ & & & $<.001$ \\
Never smokers & $64,817(81.1 \%)$ & $89(54.3 \%)$ & \\
Quit $\geq 30$ & $4738(5.9 \%)$ & $19(11.6 \%)$ & \\
Quit 20-29.9 years & $3601(4.5 \%)$ & $15(9.2 \%)$ & \\
Quit 10-19.9 years & $3170(4.0 \%)$ & $17(10.4 \%)$ & \\
Quit 5-9.9 years & $1394(1.8 \%)$ & $7(4.3 \%)$ & \\
Quit 1-4.9 years & $1199(1.5 \%)$ & $8(4.9 \%)$ & \\
Quit <1 year & $961(1.2 \%)$ & $9(5.5 \%)$ & \\
Average Number of & & & \\
Cigarettes Per Day & & & \\
None & $64,906(81.1 \%)$ & $89(54.3 \%)$ & \\
Less than 8.5 & $7677(9.6 \%)$ & $27(16.5 \%)$ & \\
Greater or equal to 8.5 & $7461(9.3 \%)$ & $48(29.3 \%)$ & \\
Non-Melanoma Skin Cancer & & & \\
No & $74,529(93.3 \%)$ & $142(86.6 \%)$ & \\
Yes & $5351(6.7 \%)$ & $22(13.4 \%)$ & \\
\hline
\end{tabular}

Values are presented as mean \pm SD or no. (\%)

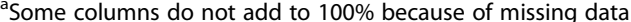

${ }^{b}$ Years of Pre-Study Residence within 10 miles of Enrollment Address

'Distance of Moving During Follow-up of Initial Place of Residence

exposure surface (average of years 2000-2001) generated through GIS-based inverse-distance-weighted (IDW) interpolation of monitored data across the U.S. EPA AQS network.

Exposure assignments were based on actual subject's residence location. However, for confidentiality reason, the actual location of cases on the U.S. map was masked by placing them at the geographic center of the corresponding residential county.

$\mathrm{PM}_{2.5}$ and $\mathrm{O}_{3}$ effects

A positive association was found between ambient $\mathrm{PM}_{2.5}$ and incident lung $\mathrm{AC}$ in the two-pollutant sandwich variance estimated model with $\mathrm{O}_{3}[\mathrm{HR}=1.31(95 \% \mathrm{CI}$ : 0.92, 1.86)] for each $10 \mu \mathrm{g} / \mathrm{m}^{3}$ increment in $\mathrm{PM}_{2.5}$. This estimate was virtually identical to the estimates from the models without the sandwich variance estimate. Adding the three additional potential confounders/effect modifiers as covariates, did not change the main effect $[\mathrm{HR}=1.32$ (95\% CI: 0.93, 1.89)] (Table 2, Model 2).

No independent association with LC was found for $\mathrm{O}_{3}$ in the two-pollutant multivariable model, $\mathrm{HR}=1.01$ (95\% CI: 0.68, 1.50) for each $10 \mathrm{ppb}$ increment in $24-\mathrm{h}$ levels (Table 2, Model 1). 


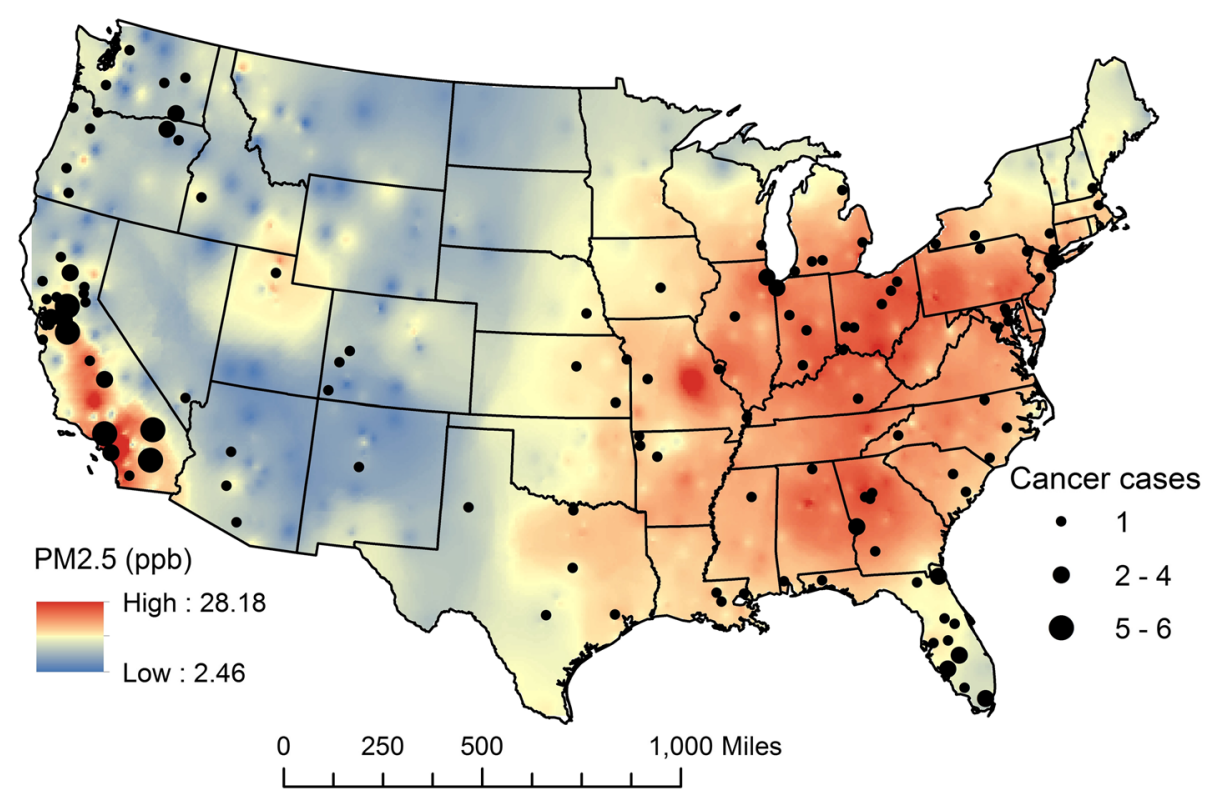

Fig. 2 Lung adenocarcinoma cases $(n=164)$ overlaid on ambient PM 2.5 surface (2000-2001 average)

\section{Effect modifications}

Among the identified three a priori potential effect modifiers (time spent outdoors, residence length and moving distance) only time spent outdoors marginally modified the association ( $p_{\text {interaction }}=0.09$ ). Among those spending more than $1 \mathrm{~h}$ /day outside, the HR increased to 1.55 (95\% CI: 1.05, 2.30) whereas no effect of ambient $\mathrm{PM}_{2.5}$ was observed for those spending less than $1 \mathrm{~h}$ /day outdoors (Table 2, Model 3).

There was no effect modification by smoking when stratifying on years since quitting smoking $\left(\mathrm{p}_{\text {interaction }}=0.99\right)$ nor when stratifying on past vs. never smokers $\left(p_{\text {interaction }}=0.42\right)$. There was, however, slightly stronger estimates for the effect of $\mathrm{PM}_{2.5}$ on lung $\mathrm{AC}$ among past smokers in the twopollutant models with $\mathrm{O}_{3}$, [HR $=1.55$ (95\% CI: 0.84, 2.89)] vs never smokers [HR $=1.13$ (95\% CI: $0.66,1.93)]$, but the 95\% CI were wide.

\section{Sensitivity analysis}

A sensitivity analysis was conducted by excluding 5373 subjects with prevalent NMSC from the final multivariable model. When limiting the analyses to those with no

Table 2 Multivariable-adjusted HRs for incident lung adenocarcinoma per $10-\mu \mathrm{g} / \mathrm{m}^{3}$ increment in mean monthly ambient PM 2.5 : single- and two-pollutant models. 79,880 AHSMOG-2 subjects (LC cases $=164$ )

\begin{tabular}{|c|c|c|c|c|c|}
\hline & Pollutant & cases & $\begin{array}{l}\text { Single Pollutant } \\
\text { HR }(95 \% \mathrm{CI})\end{array}$ & $\begin{array}{l}\text { Two Pollutant }{ }^{a} \\
\text { HR }(95 \% \mathrm{Cl})\end{array}$ & $\begin{array}{l}\text { Two Pollutant } \\
\text { HR }(95 \% \text { Cl) }\end{array}$ \\
\hline \multirow[t]{2}{*}{ Model 1} & $\mathrm{PM}_{2.5}$ & 164 & $1.31(0.87,1.97)$ & $1.31(0.87,1.97)$ & $1.31(0.92,1.86)$ \\
\hline & $\mathrm{O}_{3}$ & & & $1.01(0.68,1.50)$ & $1.01(0.69,1.47)$ \\
\hline \multirow[t]{2}{*}{ Model 2} & $\mathrm{PM}_{2.5}$ & 164 & $1.32(0.88,1.99)$ & $1.32(0.88,2.00)$ & $1.32(0.93,1.89)$ \\
\hline & $\mathrm{O}_{3}$ & & & $1.02(0.68,1.51)$ & $1.02(0.70,1.47)$ \\
\hline \multicolumn{6}{|l|}{ Model 3} \\
\hline Outdoors $<1$ & $\mathrm{PM}_{2.5}$ & 39 & $0.75(0.32,1.75)$ & $0.75(0.32,1.75)$ & $0.75(0.35,1.61)$ \\
\hline Outdoors $\geq 1$ & $\mathrm{PM}_{2.5}$ & 125 & $1.55(0.98,2.46)$ & $1.55(0.98,2.46)$ & $1.55(1.05,2.30)$ \\
\hline
\end{tabular}

Sensitivity Analysis

Model 4

Excluding NMSC

$\mathrm{PM}_{2.5}$

142

$1.62(1.04,2.50)$

$1.62(1.04,2.51)$

$1.62(1.11,2.36)$

Model 1- Adjusted for gender, educational level, race, and nested covariates: smoking status, years since quit smoking, and average number of cigarettes per day Model 2-Model $1+$ outdoors, residence length, moving distance, NMSC

Model 3-Model 1+ outdoors + $\mathrm{PM}_{2.5}{ }^{*}$ outdoors (2 levels of outdoors: $<1 \& \geq 1 \mathrm{~h} /$ day)

Model 4-Model 1, but excluding prevalent NMSC ${ }^{\mathrm{a}}$ Model [1-4] - adjusted for $\mathrm{O}_{3}$ with increments of $10 \mathrm{ppb}$

${ }^{a}$ Model [1-4] - adjusted for $\mathrm{O}_{3}$ with increments of $10 \mathrm{ppb}$

${ }^{\mathrm{b}}$ Model [1-4] - with Sandwich variance estimate 
prevalent NMSC, the $\mathrm{HR}$ for lung $\mathrm{AC}$, associated with $\mathrm{PM}_{2.5}$, was strengthened [HR $\left.=1.62(95 \% \mathrm{CI}: 1.11,2.36)\right]$ (Table 2, Model 4).

\section{Discussion}

Our finding of a $31 \%$ increase in incident lung $\mathrm{AC}$ associated with each $10 \mu \mathrm{g} / \mathrm{m}^{3}$ increment in ambient $\mathrm{PM}_{2.5}$ concentration is in line with findings of the NHS (33\% increase) [12] and stronger than that reported by the Netherlands Study (25\% increase) [19]. The ESCAPE meta-analytic study found an even stronger effect (55\% increase) per $5 \mu \mathrm{g} / \mathrm{m}^{3}$ incremental increase in $\mathrm{PM}_{2.5}$ [13].

The NHS, the largest study of incident LC among US women to date, and with a follow-up of 16 years, examined the relation of lung AC incidence with ambient PM and residential distance to roadways. Similar to our findings, an increase in lung $\mathrm{AC}$ was observed for each $10 \mu \mathrm{g} / \mathrm{m}^{3}$ increment of $\mathrm{PM}_{2.5}$ (HR $=1.33$; 95\% CI: 0.921.93). The association was even stronger when limiting the analyses to never smokers or smokers who quit $\geq 10$ years ago ( $\mathrm{HR}=1.66$; 95\% CI: 0.81-3.42) [12] which is different from our data where the estimates was somewhat higher among the past smokers, although with wide confidence intervals due to small numbers. Also, the reference groups were different in that it included current smokers in the NHS, but non-smoking recent ( $<10$ years ago) quitters in our analyses.

An extended follow-up of the prospective Netherlands Cohort Study on Diet and Cancer (NLCS) investigated the association of air pollution with incident lung cancer by histological subtypes and evaluated the impact of air pollution exposure measurement error on the risk of incident lung cancer [19]. After adjusting for measurement error using regression calibration, the HR for incident lung AC increased from 1.12 (95\% CI: 0.74-1.70) in the multivariable model to 1.25 (95\% CI 0.54-2.89) per $10 \mu \mathrm{g} / \mathrm{m}^{3}$ increment in $\mathrm{PM}_{2.5}$. The authors conclude that their measurement error adjustments "provides a sense of the level of underestimation in studies that are unable to perform this correction for measurement error bias". Unfortunately, we were not able to do measurement error adjustment, but this latest report from the NLCS suggests that our findings may be underestimates of the true association between ambient $\mathrm{PM}_{2.5}$ and incident lung AC.

Compared to our study with 164 cases, the larger European Study of Cohorts for Air Pollution Effects (ESCAPE), with $727 \mathrm{AC}$ cases and 12.8 years of follow-up, reported a stronger HR of 1.55 (95\% CI: 1.05-2.29) for each $5 \mu \mathrm{g} / \mathrm{m}^{3}$ increment in $\mathrm{PM}_{2.5}$ [13]. In another metaanalysis of 17 cohorts, Hamra et al. [21] reported a meta-estimate HR of lung AC of 1.40 (95\% CI: 1.071.83) for each $10 \mu \mathrm{g} / \mathrm{m}^{3}$ increase in $\mathrm{PM}_{2.5}$.
A Canadian case control study [11] reported increased odds of incident lung AC (OR $=1.27$ (95\% CI: 0.841.90) for each $10 \mu \mathrm{g} / \mathrm{m}^{3}$ increase in $\mathrm{PM}_{2.5}$ and $\mathrm{OR}=1.17$ (95\% CI: 1.01-1.35) for each $10 \mathrm{ppb}$ increase in $\mathrm{NO}_{2}$. For each $10 \mathrm{ppb}$ increase in $\mathrm{O}_{3}$ the OR was 1.04 (95\% CI: 0.74-1.44), very similar to our findings.

Although not a study of $\mathrm{PM}_{2.5}$ and lung AC per se, another case control study in Canada investigated the associations between incident lung cancer subtypes and occupational exposure to diesel and gasoline engine emissions, both known markers of $\mathrm{PM}_{2.5}$ pollution. At least 10 years occupational exposure to diesel engine emission was not associated with lung $\mathrm{AC}$ and 10 years exposure to gasoline engine emissions was only weakly associated with lung AC with adjusted ORs of 0.94 (95\% CI: $0.72-1.25$ ) and 1.10 (95\% CI: 0.83-1.44), respectively. The potential for exposure misclassification and the inability to take into account non-occupational exposure to gasoline in particular, in the authors' view, implied that the risks were likely to be underestimated [31].

Nitrogen oxides $\left(\mathrm{NO}_{\mathrm{x}}\right)$ are also considered markers of $\mathrm{PM}_{2.5}$. A Danish study, using outcome data from three prospective cohort studies, however, found no clear association between ambient $\mathrm{NO}_{\mathrm{x}}$ and incidence of lung AC [32].

We found no association between lung cancer and ozone levels, even after controlling for $\mathrm{PM}_{2.5}$ in twopollutant models. Only a few studies have assessed the relationship of ozone with $\mathrm{LC}$ and most have found no association [11, 33].

In contrast, in the previous and smaller AHSMOG-1 study where a different ozone metric was used, we found an increased risk of LC among males [23] with a relative risk RR of 3.56 (95\% CI: 1.35, 9.42) for every $556 \mathrm{~h} /$ year that the males experienced $\mathrm{O}_{3}$ levels of $100 \mathrm{ppb}$ or higher. There was no association between ambient $\mathrm{O}_{3}$ levels and incident LC among females. In that study, males, as compared to females, spent considerably more time outdoors, especially in the summer, and reported twice as much vigorous exercise outdoors in the summer, when $\mathrm{O}_{3}$ was higher. Further, these AHSMOG-1 findings were related to exceedance frequencies of $\mathrm{O}_{3}$ (i.e. hours/year that an air pollutant exceeded a specific concentration) which are a different $\mathrm{O}_{3}$ metric than the 24-h average used in the present study.

We found that the HR for lung AC associated with ambient $\mathrm{PM}_{2.5}$ was strengthened when excluding prevalent NMSC. As far as we can tell, among 15 studies assessing the relationship between ambient air pollution and lung AC, none of them specifically say they have excluded NMSC and only one of 35 studies which assessed the association between ambient NOx and total LC has specifically mentioned excluding NMSC [34]. Several studies [26-29], but not all [35], have reported increased 
risk of non-cutaneous cancer among subjects with prevalent NMSC. Silverberg and Ratner found that both NMSC and melanoma were associated with increased odds of non-cutaneous malignancies including lung cancer [26]. Rees, et al. reported increased risk of lung cancer among subjects with prevalent basal cell cancer (BCC) $\mathrm{HR}=1.14$ (95\% CI: 0.68-1.90), but no increased risk after squamous cell skin carcinomas (SQCC) [27]. A prospective study in Switzerland found that prevalent SQCC was associated with an excess risk of lung cancer standardized incidence ratio (SIR) [1.3 (95\% CI: 1.01.6)], and other non-cutaneous cancers [28]. A study in Finland followed BCC patients for 9 years and found increased risk of several non-cutaneous sites, including lung/trachea cancer SIR = 1.12 (95\% CI:1.06-1.17) [29]. Levi, et al., however, concluded that subjects diagnosed with BCC do not have a generalized excess risk of noncutaneous neoplasms, with the exception of nonHodgkin's lymphoma and cancers of the lip and salivary glands [35]. To our knowledge, the findings of a stronger association between ambient fine particulates and risk of lung AC when excluding prevalent NMSC have not been reported previously. Replicating these findings in other large cohort studies is important. If confirmed, possible biologic mechanisms are unclear and speculative at this time. Serum vitamin D levels have been found to be inversely related to LC incidence $[36,37]$ and diets high in fruits and vegetables have also been reported as protective for LC development [38-40]. However, to our knowledge, no previous study has assessed possible effect modifications of NMSC on the association between smoking or air pollution on risk of LC. It is possible that subjects with prevalent NMSC modify their lifestyle by spending less time outdoors, at least during daylight hours when sunlight is strong and air pollution is higher, eating a more healthy diet and taking vitamin D supplements. But these possible relationships, as well as other possible biologic mechanisms, need to be explored further. Our findings, however, do raise the question of whether exclusion of prevalent NMSC should be routine when assessing risk of LC associated with ambient air pollution in longitudinal studies.

\section{Strengths and limitations of the study}

There are several strengths of this study. This is a health conscious non-smoking population where almost $81 \%$ have never smoked and where $55 \%$ of past smokers quit more than 20 years ago. The proportion who currently use alcohol is low and the actual use among the current drinkers is very low. Thus there is minimal confounding by smoking or alcohol. Another strength is that we have ambient air pollution estimates at the residence street level which makes individual ambient air pollution estimates more valid. Since Black subjects have been under- represented in most cohort studies, the relatively large proportion (28\%) of Black subjects in this study is important. The validity of the study is strengthened by our ability to adjust for time spent outdoors, length of residence at enrollment address and moving history during follow-up as well as the fact that we were able to do linkage to state cancer registries to obtain lung cancer incidence.

One potential limitation is that we did not specifically ask about environmental tobacco smoke (ETS) in our baseline questionnaire. However, all subjects in this cohort are Adventists and typically live in households with other Adventists and so we believe the prevalence of ETS is very low especially because smoking in the workplace was unlikely in the early 2000's given legislation in the various states [41]. We only assessed ambient air pollution during the 2 years immediately prior to study start and this could potentially attenuate our results. Another possible and unmeasured source of ambient $\mathrm{PM}_{2.5}$ is tailpipe emissions which is known to have higher concentrations of $\mathrm{PM}_{2.5}$ than the typical residential areas $[42,43]$. We have no information on how many hours subjects spend in motor vehicle traffic, but such information at the individual level could potentially modify the observed associations we have reported. Lastly, the residence-specific air pollution estimates were based on air quality monitoring stations, and not on personal monitoring, and this may result in unknown amounts of misclassification. But such misclassification is most likely non-differential and would tend to bias results towards the null.

\section{Conclusions}

In summary, this study showed a $31 \%$ increase in incident lung $\mathrm{AC}$ associated with incremental increase in ambient $\mathrm{PM}_{2.5}$ concentrations among non-smokers. Our findings are in line with other cohort studies and also support the conclusions of IARC in classifying outdoor air pollution and $\mathrm{PM}_{2.5}$ as carcinogenic. The potential impact of different chemical compositions of $\mathrm{PM}_{2.5}$ should be evaluated in future studies. The observed interaction with time spent outdoors is important and underscores the importance of legislation to control ambient levels of particulate air pollution. Our findings that the association between ambient air pollution and $\mathrm{AC}$ of the lung is strengthened when excluding prevalent NMSC has, to our knowledge, not been reported before and needs further study in other large cohort studies. If replicated, this finding could result in altered practice regarding exclusion of prevalent NMSC when assessing incident non-cutaneous cancers, especially those related to air pollution. Our findings are important for the public as they make informed choices about their lifestyle and place of residence. 


\section{Abbreviations}

AC: Adenocarcinoma; AHS-2: Adventist Health Study-2; AHSMOG: Adventist Health Study on the Health Effects of Smog; AQS: Air Quality System; BCC: Basal Cell Cancer; BMI: Body Mass Index; Cl: Confidence Interval; EPA: Environmental Protection Agency; ESCAPE: European Study of Cohorts for Air Pollution Effects; ETS: Environmental Tobacco Smoke; GIS: Geographic Information Systems; HR: Hazard Ratio; ICD-O-3: International Classification of Diseases for Oncology; IDW: Inverse-Distance-Weighted; IRB: Institutional Review Board; LC: Lung Cancer; Log: Logarithm; NDI: National Death Index; NLCS: Netherlands Cohort Study; NMSC: Non-Melanoma Skin Cancer; NOx: Nitrogen Oxides; $\mathrm{O}_{3}$ : Ozone; OR: Odds Ratio; $\mathrm{PM}_{2.5}$ : Particulate Matter with Aerodynamic Diameter Smaller than $2.5 \mu \mathrm{m}$; RR: Relative Risk; SAS: SAS Institute - Cary, NC, USA; SIR: Standardized Incidence Ratio; SQCC: Squamous Cell Cancer

\section{Acknowledgements}

Cancer incidence data have been provided by the 'Alaska Cancer Registry', 'Alabama Statewide Cancer Registry', 'Arizona Cancer Registry', 'Arkansas Central Cancer Registry', 'California Cancer Registry', 'Colorado Central Cancer Registry', 'Connecticut Tumor Registry', 'District of Columbia Cancer Registry', 'Delaware Cancer Registry', 'Florida Cancer Data System', 'Georgia Comprehensive Cancer Registry', 'Hawaii Tumor Registry', 'Cancer Data Registry of Idaho', 'lowa Cancer Registry', 'Illinois State Cancer Registry', 'Indiana State Cancer Registry', 'Kansas Cancer Registry', 'Kentucky Cancer Registry', 'Louisiana Tumor Registry', 'Maryland Cancer Registry', 'Massachusetts Cancer Registry', 'Michigan Cancer Surveillance System', 'Minnesota Cancer Surveillance System', 'Mississippi Cancer Registry', 'Missouri Cancer Registry and Research Center', 'Montana Central Tumor Registry', 'Nebraska Cancer Registry', 'Nevada Central Cancer Registry', 'New Hampshire State Cancer Registry', 'New Jersey State Cancer Registry', 'New Mexico Tumor Registry', 'New York State Cancer Registry', 'North Carolina Central Cancer Registry', 'North Dakota Statewide Cancer Registry', 'Ohio Cancer Incidence Surveillance System', 'Oklahoma Central Cancer Registry', 'Oregon State Cancer Registry', 'Pennsylvania Cancer Registry', 'Rhode Island Cancer Registry', 'South Carolina Central Cancer Registry', 'South Dakota Cancer Registry', 'Tennessee Cancer Registry', Texas Cancer Registry', 'Utah Cancer Registry, NCl Contract HHSN261201300071', Vermont Cancer Registry', Virginia Cancer Registry', 'Washington State Cancer Registry', 'West Virginia Cancer Registry', 'Wyoming Cancer Surveillance Program'. The results reported here and the conclusions based on them are the sole responsibility of the authors. The authors assume full responsibility for analyses and interpretation of the data. None of the funders (NIH, World Cancer Research Fund, UK or EPA) had a role in the study design, conduct of the study, analysis of data, interpretation of findings or the preparation of the manuscript.

\section{Funding}

This research was funded partially by EPA (Grant No. CR 83054701) and by National Institutes of Health (NIH)/National Cancer Institute (NCI): grant no. 5U01CA152939 and World Cancer Research Fund, UK: grant no. 2009/93. None of the funders had a role in the study design, conduct of the study, analysis of data, interpretation of findings or the preparation of the manuscript.

\section{Availability of data and materials}

Please contact author for data requests.

\section{Authors' contributions}

LG and SFK designed research; LG conducted research; SS provided air pollution exposure models and PM2.5 monthly exposure surface maps; DS and $M G$ analyzed data; $L G, W L B$, and RK wrote the paper; SFK had primary responsibility for final content. All authors read and approved the final manuscript. The results reported here and the conclusions based on them are the sole responsibility of the authors. The authors assume full responsibility for analyses and interpretation of the data.

\section{Competing interests}

The authors declare that they have no competing interests.

\section{Ethics approval and consent to participate}

Approved by the Loma Linda University Institutional Review Board (IRB), and by the IRBs of participating cancer registries, as required. Written informed consent was obtained from all participants upon enrollment into the parent study (AHS-2) and this included subsequent analyses using de-identified data.

\section{Publisher's Note}

Springer Nature remains neutral with regard to jurisdictional claims in published maps and institutional affiliations.

\section{Author details}

${ }^{1}$ School of Allied Health Professions, Loma Linda University, Loma Linda, CA, USA. ${ }^{2}$ Center for Nutrition, Healthy Lifestyle, and Disease Prevention, School of Public Health, Loma Linda University, Loma Linda, CA, USA. ${ }^{3}$ Adventist Health Study-2, School of Public Health, Loma Linda University, Loma Linda, CA, USA. ${ }^{4}$ Center for Community Resilience, School of Public Health, Loma Linda University, Loma Linda, CA, USA. ${ }^{5}$ Loma Linda University School of Public Health, 24951 North Circle Drive, Nichol Hall 2005, Loma Linda, CA 92350, USA

Received: 29 September 2016 Accepted: 6 June 2017

Published online: 24 June 2017

\section{References}

1. American Cancer Society. PDQ ${ }^{\oplus}$ - ACS's Comprehensive Cancer Database. Detailed Guide - Lung Cancer (Non-Small Cell). https://www.cancer.org/ content/dam/CRC/PDF/Public/8703.00.pdf. Accessed 6 Dec 2015.

2. American Cancer Society. PDQ ${ }^{\oplus}$ - ACS's Comprehensive Cancer Database. Cancer Facts \& Figures 2016. http://www.cancer.org/acs/groups/content/ @research/documents/document/acspc-047079.pdf. Accessed 19 Jan 2016.

3. Lortet-Tieulent J, Soerjomataram I, Ferlay J, Rutherford M, Weiderpass E, Bray F. International trends in lung cancer incidence by histological subtype: adenocarcinoma stabilizing in men but still increasing in women. Lung Cancer. 2014;84(1):13-22.

4. Houston KA, Henley SJ, Li J, White MC, Richards TB. Patterns in lung cancer incidence rates and trends by histologic type in the United States, 20042009. Lung Cancer. 2014;86(1):22-8.

5. Lewis DR, Check DP, Caporaso NE, Travis WD, Devesa SS. US lung cancer trends by histologic type. Cancer. 2014;120(18):2883-92.

6. Kong J, Xu F, He M, Chen K, Qian B. The incidence of lung cancer by histological type: a population-based study in Tianjin, China during 19812005. Respirology. 2014;19(8):1222-8.

7. Chen F, Jackson H, Bina WF. Lung adenocarcinoma incidence rates and their relation to motor vehicle density. Cancer Epidemiol Biomark Prev. 2009;18(3):760-4.

8. Chen F, Cole P, Bina WF. Time trend and geographic patterns of lung adenocarcinoma in the United States, 1973-2002. Cancer Epidemiol Biomark Prev. 2007;16(12):2724-9.

9. Tseng CY, Huang YC, Su SY, et al. Cell type specificity of female lung cancer associated with sulfur dioxide from air pollutants in Taiwan: an ecological study. BMC Public Health. 2012;12:1-8.

10. Hamra GB, Laden F, Cohen AJ, Raaschou-Nielsen O, Brauer M, Loomis D. Lung cancer and exposure to nitrogen dioxide and traffic: a systematic review and meta-analysis. Environ Health Perspect. 2015;123:1107-12.

11. Hystad P, Demers PA, Johnson KC, Carpiano RM, Brauer M. Long-term residential exposure to air pollution and lung cancer risk. Epidemiology. 2013;24(5):762-72.

12. Puett RC, Hart JE, Yanosky JD, et al. Particulate matter air pollution exposure, distance to road, and incident lung cancer in the nurses' health study cohort. Environ Health Perspect. 2014;122:926-32.

13. Raaschou-Nielsen O, Andersen ZJ, Beelen R, et al. Air pollution and lung cancer incidence in 17 European cohorts: prospective analyses from the European study of cohorts for air pollution effects (ESCAPE). The lancet oncology. 2013;14(9):813-22.

14. Beelen $R$, Hoek $G$, Van Den Brandt PA, et al. Long-term exposure to trafficrelated air pollution and lung cancer risk. Epidemiology. 2008;19(5):702-10.

15. Pope CA 3rd, Burnett RT, Thun MJ, et al. Lung cancer, cardiopulmonary mortality, and long-term exposure to fine particulate air pollution. JAMA. 2002;287:1132-41. 
16. Naess O, Nafstad P, Aamodt G, Claussen B, Rosland P. Relation between concentration of air pollution and cause-specific mortality: four-year exposures to nitrogen dioxide and particulate matter pollutants in 470 neighborhoods in Oslo, Norway. Am J Epidemiol. 2007;165:435-43.

17. Dockery DW, Pope CA, Xu X, et al. An association between air pollution and mortality in six us cities. N Engl J Med. 1993;329:1753-9.

18. Attfield MD, Schleiff PL, Lubin JH, et al. The diesel exhaust in miners study: a cohort mortality study with emphasis on lung cancer. J Natl Cancer Inst. 2012;104(11):869-83.

19. Hart JE, Spiegelman D, Beelen $R$, et al. Long-term ambient residential trafficrelated exposures and measurement error-adjusted risk of incident lung cancer in the Netherlands cohort study on diet and cancer. Environmental health: a global access science source. 2015;2:1-35.

20. International Agency for Research on Cancer. PDQ ${ }^{\circledR}$ - IARC's Comprehensive Cancer Database. Outdoor air pollution a leading environmental cause of cancer deaths. World Health Organization. 2013. https://www.iarc.fr/en/ media-centre/iarcnews/pdf/pr221_E.pdf. Accessed 25 Aug 2015.

21. Hamra GB, Guha N, Cohen A, et al. Outdoor particulate matter exposure and lung cancer: a systematic review and meta-analysis. Environ Health Perspect. 2014;122:906-11.

22. Gharibvand L, Shavlik D, Ghamsary M, Beeson WL, Soret S, Knutsen R, et al. The association between ambient fine particulate air pollution and lung cancer incidence: results from the AHSMOG-2 study. Environ Health Perspect. 2017;125(3):378.

23. Beeson WL, Abbey DE, Knutsen SF. Long-term concentrations of ambient air pollutants and incident lung cancer in California adults: results from the AHSMOG study. Adventist health study on Smog. Environ Health Perspect. 1998;106(12):813.

24. Butler TL, Fraser GE, Beeson WL, et al. Cohort profile: the Adventist health study-2 (AHS-2). Int J Epidemiol. 2008;37(2):260-5.

25. ESRI. ArcGIS Desktop: Release 10. PDQ ${ }^{\circledR}$ - ESRI's Comprehensive Mapping Software Database. http://desktop.arcgis.com/en/\#data-management. Accessed 20 June 2015.

26. Silverberg Jl, Ratner D. Associations of non-melanoma skin cancer and melanoma, extra-cutaneous cancers and smoking in adults: a US population-based study. J Eur Acad Dermatol Venereol. 2014;29(7):1389-97.

27. Rees JR, Zens MS, Gui J, Celaya MO, Riddle BL, Karagas MR. Non melanoma skin cancer and subsequent cancer risk. PLoS One. 2014;9(6):1-8.

28. Levi F, Randimbison L, La Vecchia C, Erler G, Te VC. Incidence of invasive cancers following squamous cell skin cancer. Am J Epidemiol. 1997;146(9): 734-9.

29. Milán T, Pukkala E, Verkasalo PK, et al. Subsequent primary cancers after basal-cell carcinoma: a nationwide study in Finland from 1953 to 1995. Int J Cancer. 2000;87(2):283-8.

30. Lin DY. Cox regression analysis of multivariate failure time data: the marginal approach. Stat Med. 1994;13(21):2233-47.

31. Villeneuve PJ, Parent M-É, Sahni V, Johnson KC, Group CCRER. Occupational exposure to diesel and gasoline emissions and lung cancer in Canadian men. Environ Res. 2011;111(5):727-35.

32. Raaschou-Nielsen $\mathrm{O}$, Bak $\mathrm{H}$, Sorensen $\mathrm{M}$, et al. Air pollution from traffic and risk for lung cancer in three Danish cohorts. Cancer Epidemiol Biomarkers Prev. 2010;19(5):1284-91.

33. Vineis , , Hoek G, Krzyzanowski M, Vigna-Taglianti F, Veglia F, Airoldi L, et al. Air pollution and risk of lung cancer in a prospective study in Europe. Int J Cancer. 2006;119(1):169-74.

34. Raaschou-Nielsen O, Andersen ZJ, Hvidberg M, Jensen SS, Ketzel M, Sørensen $M$, et al. Lung cancer incidence and long-term exposure to air pollution from traffic. Environ Health Perspect. 2011;119(6):860.

35. Levi F, La Vecchia C, Te VC, Randimbison L, Erler G. Incidence of invasive cancers following basal cell skin cancer. Am J Epidemiol. 1998;147(8):722-6.

36. Zhang L, Wang S, Che X, Li X. Vitamin D and lung cancer risk: a comprehensive review and meta-analysis. Cell Physiol Biochem. 2015;36(1): 299-305.

37. Kilkkinen A, Knekt P, Heliovaara M, Rissanen H, Marniemi J, Hakulinen T, et al. Vitamin D status and the risk of lung cancer: a cohort study in Finland. Cancer Epidemiol Biomarkers Prev. 2008;17(11):3274-8.

38. Fraser GE, Beeson WL, Phillips RL. Diet and lung cancer in California seventh-day Adventists. Am J Epidemiol. 1991;133(7):683-93.

39. Smith-Warner SA, Spiegelman D, Yaun SS, Albanes D, Beeson WL, Van Den Brandt PA, et al. Fruits, vegetables and lung cancer: a pooled analysis of cohort studies. Int J Cancer. 2003;107(6):1001-11.
40. Vieira AR, Abar L, Vingeliene S, Chan DS, Aune D, Navarro-Rosenblatt D, et al. Fruits, vegetables and lung cancer risk: a systematic review and metaanalysis. Ann Oncol. 2016;27(1):81-96.

41. Americans for Nonsmokers' Rights. $P D Q^{\oplus}$ - ANR's Comprehensive Smokefree Database. U.S. 100\% Smokefree Laws in Non-Hospitality Workplaces and Restaurants and Bars. http://www.no-smoke.org/pdf/WRBLawsMap.pdf. Accessed 18 Dec 2015.

42. Weichenthal S, Van Ryswyk K, Kulka R, Sun L, Wallace L, Joseph L. In-vehicle exposures to particulate air pollution in Canadian metropolitan areas: the urban transportation exposure study. Environ Sci Technol. 2014;49(1): 597-605.

43. Mirabelli MC, Golan R, Greenwald R, et al. Modification of traffic-related respiratory response by asthma control in a population of car commuters. Epidemiology. 2015;20:546-55.

\section{Submit your next manuscript to BioMed Central and we will help you at every step:}

- We accept pre-submission inquiries

- Our selector tool helps you to find the most relevant journal

- We provide round the clock customer support

- Convenient online submission

- Thorough peer review

- Inclusion in PubMed and all major indexing services

- Maximum visibility for your research

Submit your manuscript at www.biomedcentral.com/submit 